ถอN 2230-3826

\title{
FORMAÇẢO ARTÍSTICO-CULTURAL DE PAIS E PROFESSORES DE ALUNOS DE INSTITUIÇŌES EDUCACIONAIS: A DANÇA EM FOCO
}

\author{
Alba Pedreira Vieira
}

Doutora em Dança pela Temple Universitụ.

Estados Unidos. Professora adjunta da

Universidade Federal de Viçosa. 
RESUMO: Um dos grandes desafios enfrentados pela dança na contemporaneidade é realizar propostas educacionais em instituições educacionais que envolvam não somente os alunos, mas também seus pais e professores. $O$ presente projeto de pesquisa, em interface com a extensão e o ensino, desenvolveu oficinas e outras atividades de dança com estudantes de 7-12 anos em três escolas públicas e três centros de educação infantil da cidade de Viçosa/MG e, também, com seus pais e professores. Delimitamos, neste artigo, nossa discussão à narração e reflexão sobre as ações e propostas artístico-culturais de dança com o público adulto. $\mathrm{O}$ trabalho com os professores, além de ter lhes permitido vivenciar a dança como arte, acrescentando essa experiência em sua formação cultural pessoal e profissional, permitiu também que eles se dessem continuidade ao trabalho (em dança ou por meio da dança) com seus alunos. Eles foram capacitados a se tornarem agentes multiplicadores das atividades do projeto. As oficinas de dança com os pais dos alunos tiveram o objetivo de promover a educação para e pela dança no sentido de enriquecer seu repertório corporal. Buscamos também promover momentos de sociabilização entre os pais, buscando ampliar a aproximação entre si mesmos e com as instituições educacionais, já que estas, muitas vezes, não Ihes oferecem, de forma sistematizada, vivências artísticas enriquecedoras. Por termos obtidos resultados bastante positivos nesse trabalho, sugerimos que projetos similares sejam desenvolvidos em outras instituições educacionais brasileiras tanto do ensino básico como da educação infantil.

PALAVRAS-CHAVE: Dança; Formação Artístico-Cultural; Pais; Professores.

ABSTRACT: A major challenge faced by the contemporary dance is to achieve educational purposes in educational institutions that involve not only students but also their parents and teachers. This research project, interface with the extension and education, has developed workshops and other activities of dance with students of 7-12 years in three schools and three early childhood education centers in the city of Viçosa / MG and also with their parents and teachers. We defined in this article, our discussion of narration and reflection on the actions and proposals artistic and cultural dance with the adult audience. Working with teachers, and has allowed them to experience dance as an art, adding that experience in his cultural and professional staff, also allowed them to give continuity to the work (or dance through dance) with their students. They were trained to become multipliers of project activities. The dance workshops with parents of students aimed to promote education and dance in order to enrich their repertoire body. We seek also to promote moments of socialization between parents, seeking to increase the proximity between themselves and with educational institutions, as they often do not offer them, in a 
systematic manner, enriching artistic experiences. Because we have obtained very positive results in this work, we suggest that similar projects are developed in other educational institutions of both the Brazilian basic education as early childhood education.

KEYWORDS: Dance, Artistic-Cultural Training, Parents, Teachers.

\section{INTRODUÇÃO'}

Muitos autores concordam que é fundamental o ensino da Arte, incluindo a Dança, em escolas e centros de educação infantil, para garantir o desenvolvimento holístico dos alunos (STINSON, 2007; BAGATINI, MARONESI \& MÜRMANN, 2006). Vários outros estudiosos (CARNEIRO, 2002; CASTRO, 2002; FERREIRA \& TRICHES, 2009; PARO, 2000), apontam a importância de envolver pais na educação de seus filhos. Arteeducadores (SGARBI, 2009; COSTA, LIMA \& VIEIRA, 2001; SÁ, 2001) ainda sugerem que, se os professores generalistas não se sentem preparados para ministrar conteúdos de Arte, em especial da Dança, que eles deveriam ser mais bem preparados por meio de formação continuada para esse fim. Mas trabalhar a Dança como arte com professores - e pais de escolas públicas não seria uma utopia considerando-se que, na maioria das vezes, nem os próprios alunos têm acesso a esse saber? Por outro lado, como garantir que o conhecimento em Dança seja desenvolvido com os alunos se, muitas vezes, nem mesmo seus pais e professores (re)conhecem o seu valor e sua diversidade?

Este artigo apresenta o recorte de um projeto que pretendeu desafiar esses dilemas. Assim, discutimos a importância de desenvolver um trabalho amplo que agrega não somente estudantes, mas também, seus pais e professores. Esse trabalho de pesquisa em interface com a extensão e o ensino desenvolveu oficinas de dança e atividades artísticas afins (por exemplo, fruição de espetáculos) com estudantes de 7-12 anos do ensino básico de escolas públicas e da educação infantil de centros educacionais da cidade de Viçosa/MG

1 Este artigo apresenta dados de um projeto de pesquisa em interface com o ensino e a extensão com apoio da do CNPq, da FAPEMIG, da FUNARBE, da CAPES e da Pró-Reitoria de Extensão e Cultura da Universidade Federal de Viçosa/ UFV por meio do programa PIBEX. 
(fotos 1 e 2) e, também, com seus pais e professores. Delimitamos o foco deste artigo na narração e reflexão sobre tais atividades artístico-culturais de dança com o público adulto.

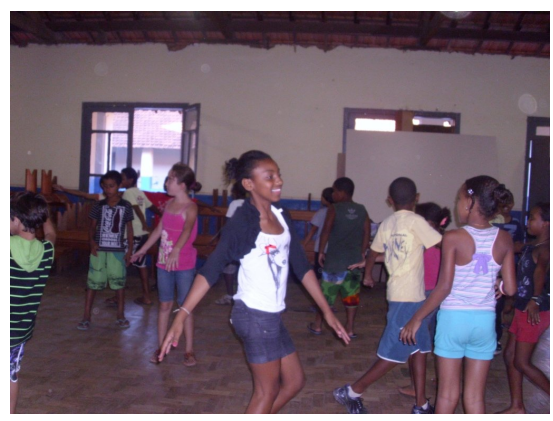

Foto 1: Oficina com Crianças - "Explorando o Espaço Pessoal” - Escola Municipal Dona Nanete

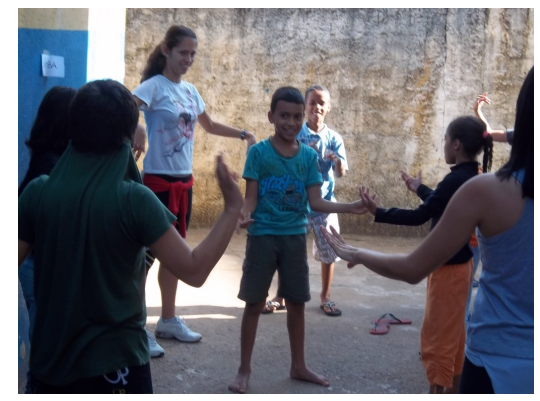

Foto 2: Bolsistas ministrando oficina de Dança com crianças - "Siga o Mestre" - Escola Municipal Anita Chequer

Viçosa é uma cidade universitária situada na Zona da Mata mineira. Apesar de possuir um nível de urbanização elevado, sua realidade social e econômica é fortemente influenciada pela comunidade acadêmica. "Em Viçosa, que tem uma população de aproximadamente 70.000 habitantes, está localizado um dos maiores e melhores centros de ensino e pesquisa na área de ciências agrárias do hemisfério sul, a Universidade Federal de Viçosa." Apesar de possuir uma excelente e reconhecida universidade, é afastada da

$2<$ http:// www.ufv.br/ dfp/LabProtecao/a\%20cidade.htm>acessado em 10 de fevereiro de 2012. 
capital do estado, Belo Horizonte, onde há uma ampla gama de oportunidades para que os cidadãos se envolvam com o mundo da cultura, o qual, segundo Nogueira (2008), é caracterizado como um locus de leituras e interpretações diversificadas do real, concretizado nas linguagens artísticas - Dança, Teatro, Artes Visuais e Música. Em Viçosa, porém, há poucos espaços permanentes de cultura, e também um número insuficiente, a nosso ver, de atividades artístico-culturais enriquecedoras.

Tais lacunas passaram a chamar nossa atenção, particularmente, em relação à formação artístico-cultural de pais e professores de alunos de escolas públicas e centros de educação infantil em Viçosa - a qual, supomos, seria 'carente'. Quando iniciamos o trabalho com esse público, em meados de 2008, já desenvolvíamos desde o início daquele ano aulas e oficinas regulares e semanais com os alunos. Mas inquietava-nos também a sensação de que faltava um envolvimento maior de toda a comunidade escolar nas nossas ações. Cresceu em nós o desejo de oportunizar aos pais e professores propostas, momentos e espaços artístico-culturais que Ihes possibilitassem vivências estéticas enriquecedoras. Fomos movidos pela necessidade de realizar intervenções que promovam a melhoria da qualidade da educação brasileira, mas entendemos que, para isso, precisamos tanto desenvolver ações com os alunos, como com seus pais e professores para que todos possam experimentar a diversidade da Arte, ampliar seus referenciais estéticos e seu saber sensível.

\section{JUSTIFICATIVA}

Vários estudos (e.g., CIA et al., 2004; CARVALHO, 2000; BHERING et al., 2002; FARIAS, 2007) discutem a importância do envolvimento dos pais na educação dos seus filhos. Mas parece haver uma lacuna em investigações sobre a formação artístico-cultural desses pais e/ou como podemos contribuir com esse processo. Pesquisadores também têm, recentemente, debatido sobre a formação cultural de professores (e.g. NOGUEIRA, 2008a; NOGUEIRA, 2008b; MORAES, 2008; LOPONTE, 2010). Assim, esse projeto buscou contribuir com as lacunas existentes e com esses debates incluindo, especificamente, a dança como o foco de propostas que atuam na formação artístico-cultural de pais e professores. Entendemos a importância desse tipo de investigação, pois possibilita o 
alargamento das experiências culturais dos sujeitos envolvidos, o que, muito provavelmente, vai influenciar positivamente na formação cultural de seus filhos e alunos.

\section{MÉTODO E PROCEDIMENTOS}

Esse trabalho foi orientado por princípios da pesquisa-ação (MCNIFF, WHITEHEAD, 2002). Para coleta de dados, foram usadas entrevistas informais e observação participante com pais e professores, além de questionários escritos com professores.

A equipe multidisciplinar foi composta por 17 membros (alunos e professores) dos Cursos de Dança e Comunicação Social da Universidade Federal de Viçosa/UFV e duas professoras da Escola Municipal Anita Chequer. $^{3}$

\section{PARTICIPANTES}

Participaram deste projeto três escolas públicas municipais e três centros de educação infantil não-municipais e filantrópicos de Viçosa/MG. No período do diagnóstico, através de entrevistas com os coordenadores e/ou diretores e/ou professores e, também de observação, foram indicadas essas seis instituições considerando-se: (1) demonstração de interesse em acolher e participar ativamente do projeto; (2) disponibilização de espaços, horários e materiais para as aulas com os alunos e oficinas com pais e professores; (3) carência de desenvolvimento de atividades culturais e artísticas com os alunos, bem com seus pais e professores. As escolas escolhidas foram: Dona Nanete, Maria José Santana e Anita Chequer; os centros de educação infantil selecionados foram: Creche Santa Terezinha, Creche Rebusca e Creche São João Batista.

\footnotetext{
${ }^{3}$ Agradecimentos aos professores da Escola Anita Chequer, Edilaine Rosado e Lúcia, e aos bolsistas e estagiários que participaram do trabalho de campo: Letícia Oliveira, Guilherme Teixeira, Fernanda Bastos, Daiane Santos, Aline Fialho, Débora Kamasche, Edlene Maldonado, Rafaela Oliveira, Isabela Vieira, Lívia Metzker, Nara Vieira, Míriam Silva, Mariana Alvarenga, Katiúscia Silva, Ricardo Pereira.
} 
As seis instituições têm diferentes perfis, seja pela população a que atendem, por sua localização e/ou estrutura. Vale ressaltar que nenhuma delas oferecia aulas com professores específicos da área de Artes, e todos os alunos e seus familiares tinham em comum serem de nível sócio-econômico baixo, não tendo, geralmente, acesso a bens culturais e artísticos diversificados e de maneira sistemática e contínua.

No primeiro ano do projeto (2008) 93 alunos participaram, em 2009103 alunos participaram, em 201072 alunos participaram, e em 2011 foram 177 alunos, totalizando 445 alunos participantes. Já o número de pais e professores variou muito nas diversas oficinas realizadas.

\section{PROCEDIMENTOS ÉTICOS}

A princípio, encaminhamos às diretoras das instituições selecionadas termos de autorização para que estas nos permitissem atuar semanalmente oferecendo oficinas de dança e as demais atividades e, posteriormente, analisássemos, discutíssemos e publicássemos os resultados dos dados coletados (incluindo as fotos), a fim de investigar o fenômeno. Encaminhamos também aos pais ou responsáveis autorizações que permitissem aos alunos a participação no projeto. As mesmas autorizações foram obtidas com os pais e professores para publicação de resultados advindos dos dados fornecidos por eles, bem como suas imagens. Optamos por não identificar seus nomes na apresentação dos resultados desta pesquisa.

Em relação às oficinas e demais propostas de formação cultural de pais e professores, convidamos todos para participarem, mas coube a eles a decisão de frequentá-las ou não. É necessário ressaltar que aqueles que decidiram participar não foram recompensados financeiramente por isso; pelo contrário, todas as atividades eram gratuitas e naquelas em que havia necessidade de deslocamento, como por exemplo, fruição de espetáculos nos teatros, aos participantes era fornecido transporte - ônibus escolar por meio de parceria com a Secretaria Municipal de Educação de Viçosa.

\section{DESENVOLVENDO A PROPOSTA: OFICINAS COM PROFESSORES E PAIS}


Ao discutir os saberes necessários à docência, Nogueira (2010) afirma que o docente deve saber não somente conteúdos específicos da sua área ou da sua disciplina; para a autora, "é fundamental que o professor tenha parâmetros estéticos mais amplos e, para isto, é importante que ele tenha uma sólida formação cultural, que lhe dê os subsídios necessários para atender às novas e velhas demandas que são colocadas no seu cotidiano" (p. 6). Seguindo essa orientação e indo além, pois incluímos também os pais nas nossas propostas, ao longo de quatro anos procuramos oferecer o maior número possível de oficinas para os professores e pais das instituições. No entanto, esse número e a frequência das atividades variaram bastante de acordo com 0 interesse e disponibilidade dos participantes (vide fotos 3 e 4 oficina com professores, e foto 5 oficina com pais).

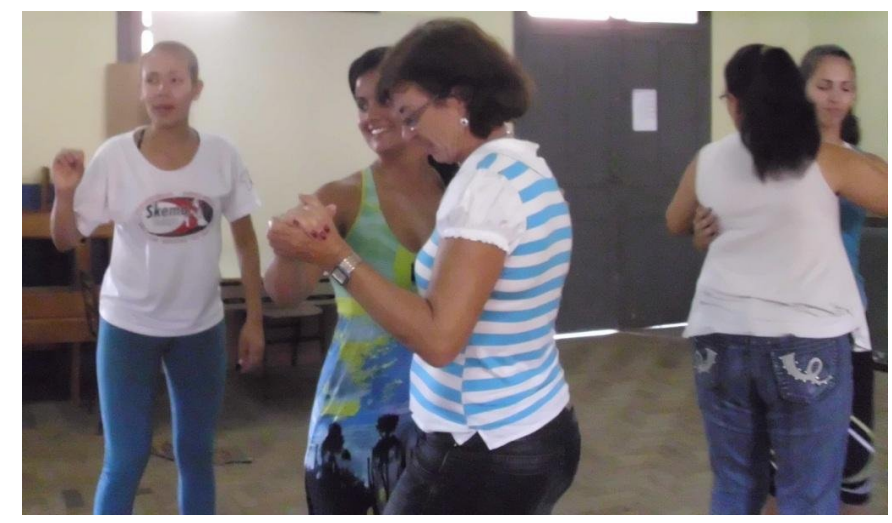

Foto 3: Oficina de Dança de Salão com Professores - Escolas Dona Nanete e Maria José Santana

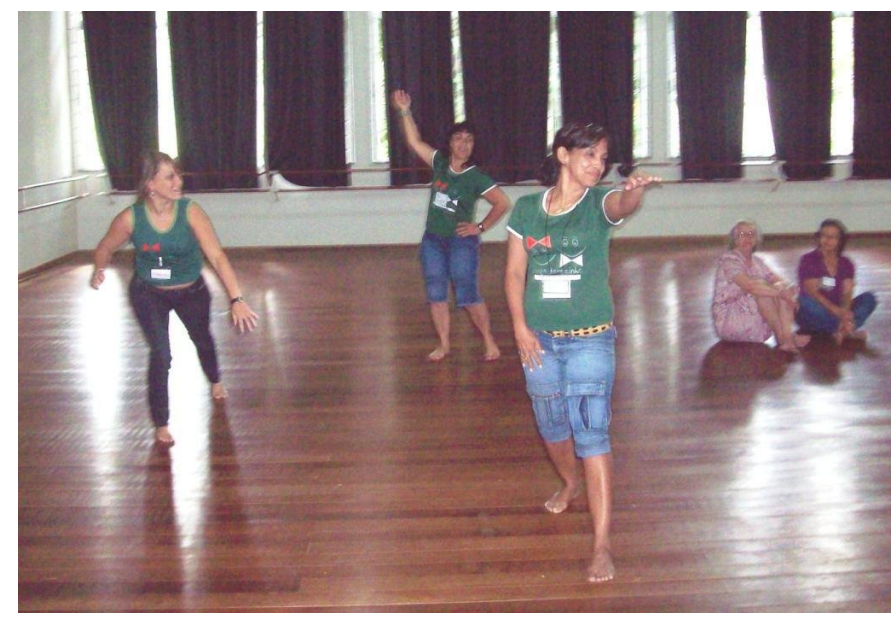


Foto 4: Oficina (trabalhando improvisação, formas, níveis e espaço) com Professores da Creche Santa Terezinha na Sede do Curso de Dança na UFV

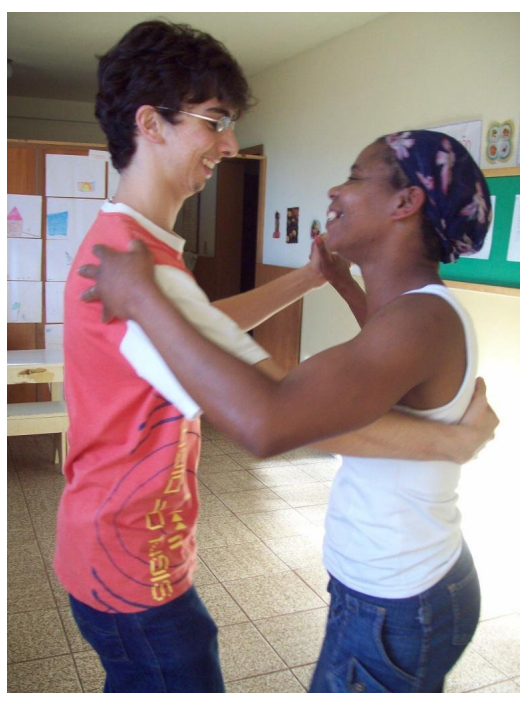

Foto 5: Oficina com Pais: Bolsista dança com uma mãe de aluno

$\mathrm{Na}$ Creche Rebusca, os funcionários afirmaram que gostariam de participar das oficinas dos professores, e, assim, eles passaram a integrar essas atividades (foto 6).

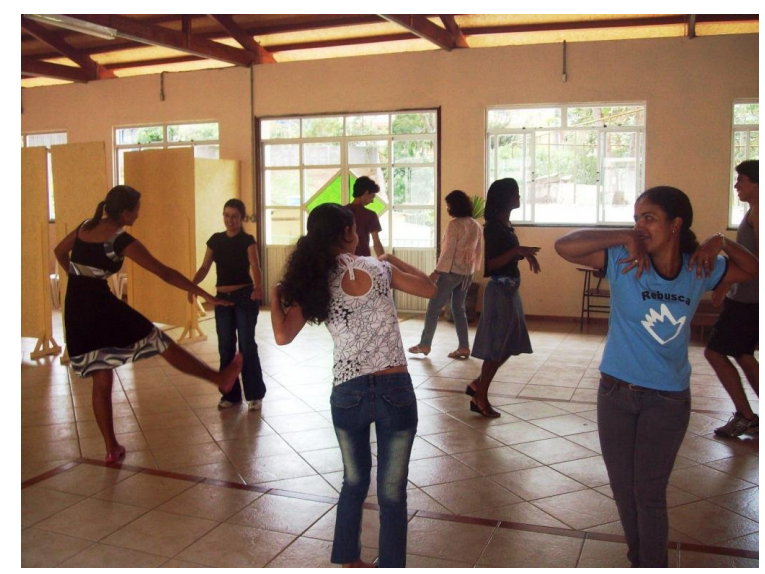

Foto 6: Oficina explorando princípios da coreologia de Laban (1990) com professores e funcionários da Creche Rebusca 
$\mathrm{Na}$ escola Dona Nanete, os funcionários também demonstraram grande interesse em participar das oficinas, então essas foram feitas com eles, semanalmente, no primeiro semestre de 2011 (fotos 7 e 8).

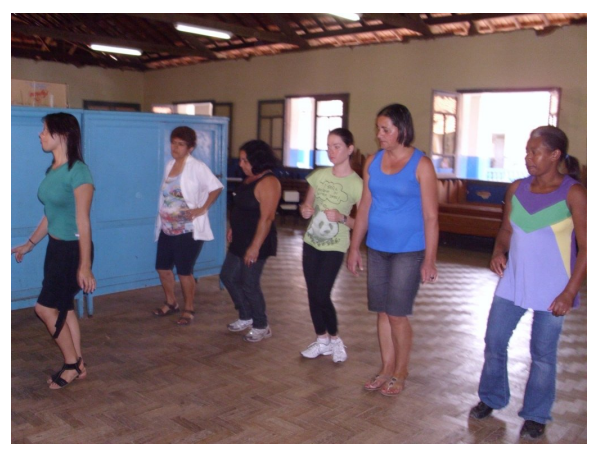

Foto 7: Oficina com Funcionários - Escola Municipal Dona Nanete

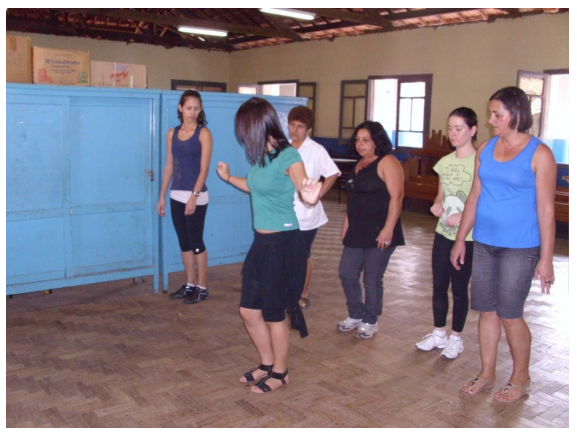

Foto 8: Oficina com Funcionários - "Aprendendo passos básicos da Dança de Salão" - Escola Municipal Dona Nanete

As oficinas com professores e demais funcionários das instituições aconteciam em horários extracurriculares ou fazíamos oficinas na hora do recreio. Além de participarem das oficinas específicas para professores, todos os docentes também participavam das aulas, alguns somente observando e outros fazendo as aulas juntamente com os professores de dança e os alunos (vide foto 9). Uma das professoras afirmou: "Aprendi muito observando e fazendo as aulas de dança com os alunos. Uso muito do que aprendi nas minhas aulas." 


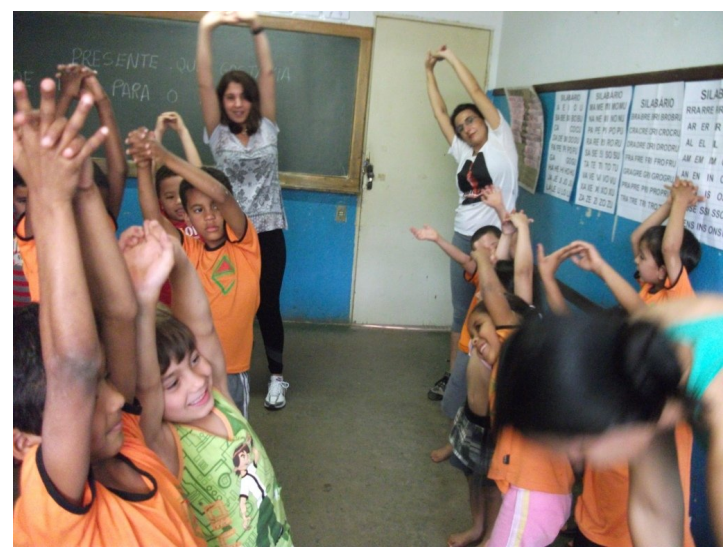

Foto 9: Professora da Escola Anita Chequer fazendo alongamento corporal na aula de dança juntamente com seus alunos e bolsista do projeto

Os conteúdos das oficinas variaram bastante, pois procuramos ser sensíveis ao desejo e necessidade dos nossos 'alunos' - nesse caso pais e professores. Assim, o que educadores em dança recomendam aos professores de dança em suas aulas com alunos do ensino básico, fundamentou também nossa práxis com os adultos participantes desse projeto: "O professor precisa ter a sensibilidade para escutar as necessidades de cada turma e assim encontrar o caminho que torne o trabalho mais adequado para cada caso específico” (MUNDIM, 2002, p. 7). É “(...) interessante levarmos em consideração o contexto dos alunos" (MARQUES, 2003, p. 32).

Fomos orientados pelas propostas de estudiosos como Bond e Stinson (2000/01; 2007), Laban (1990), Stinson (2006, 2007), Green (2007), Vieira (2007a, 2009) e outros. Portanto, o trabalho artístico-corporal do processo educacional privilegiou as 'conexões internas e externas' (VIEIRA, 2007b). A abordagem artístico-pedagógica focou no respeito mútuo, diferentes visões de mundo e concepções de corpo.

Havia uma oficina de dança para alunos e pais que acontecia à noite e semanalmente. Esse horário foi escolhido para privilegiar a presença de pais que trabalhavam durante o dia. Nesses momentos, eles podiam experimentar juntos diversas propostas que eram trabalhadas em laboratórios de improvisação (vide fotos 10 e 11). 


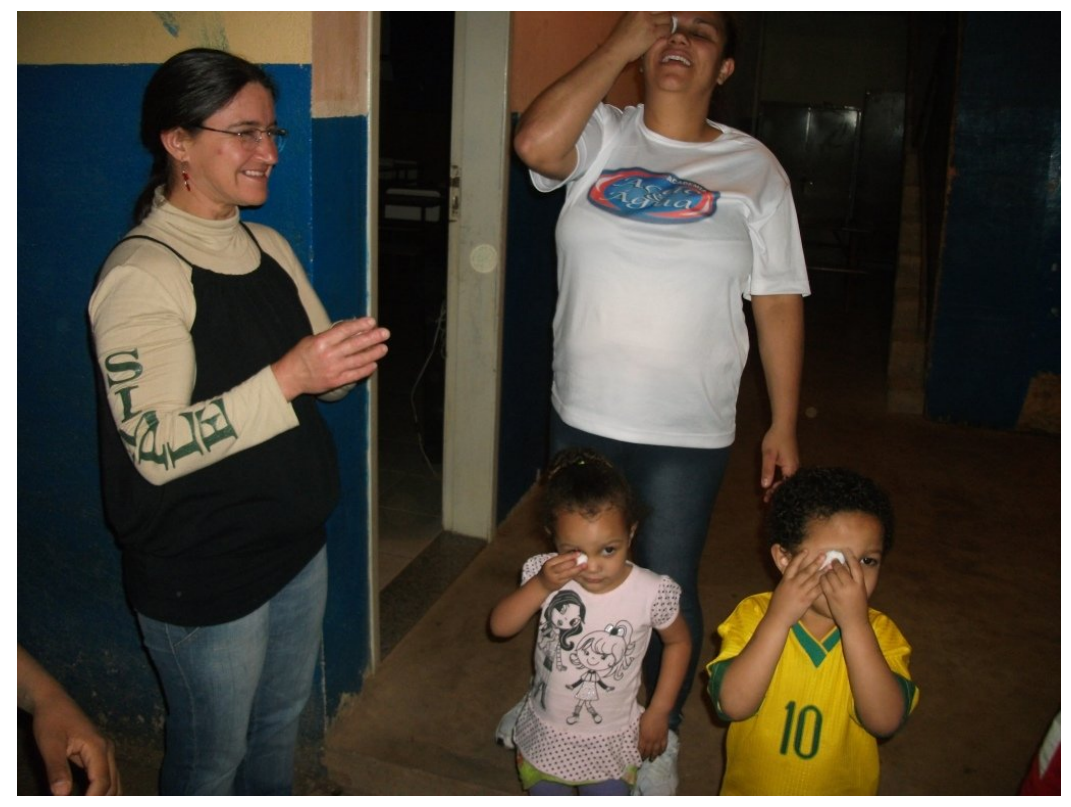

Foto 10: Alunos e mães na oficina noturna 


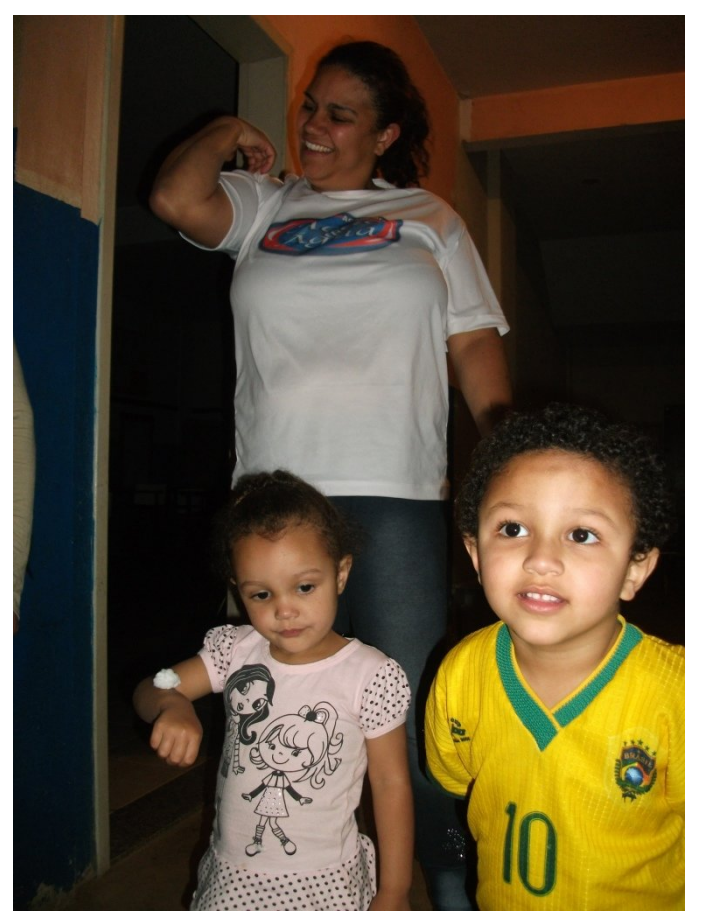

Foto 11: Alunos e mãe na oficina noturna explorando movimentos liderados por partes do corpo - cotovelo em foco

\section{PROFESSORES E PAIS EM MOMENTOS DE FRUIÇÃO}

Além das oficinas de dança, os pais e professores também puderam fruir apresentações, performances e espetáculos, de grupos e/ou artistas locais e nacionais, ao vivo de diversos estilos em teatros e no Curso de Dança da UFV (fotos 12, 13 e 14). 


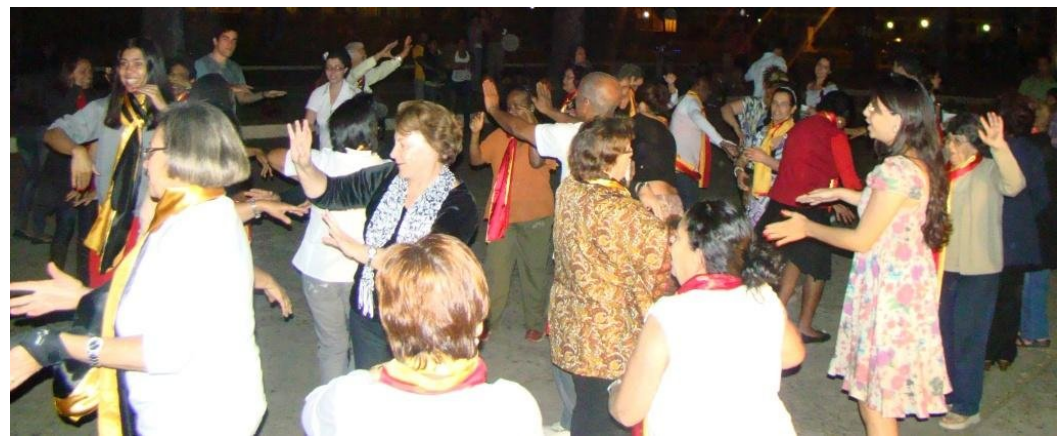

Foto 12: Professores e pais das escolas participam de Dança Coral com a comunidade viçosense em evento comemorativo aos 85 anos da UFV

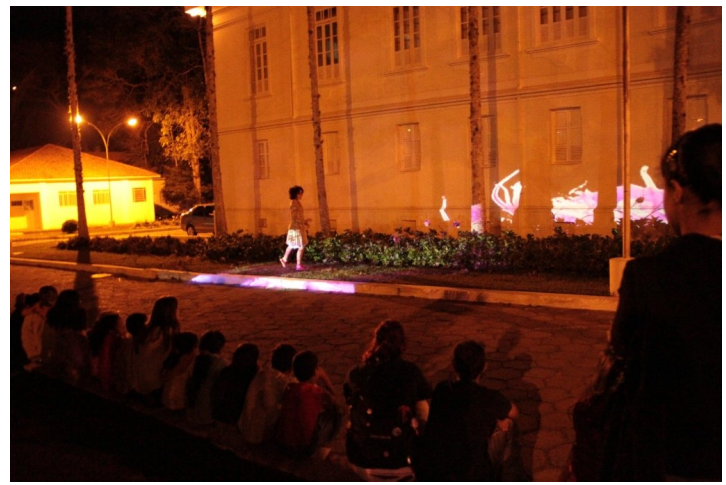

Foto 13: Professores, pais e alunos das escolas assistem a performance "Perfume para Argamassa" de Kleber Damaso e Viviane Domingos

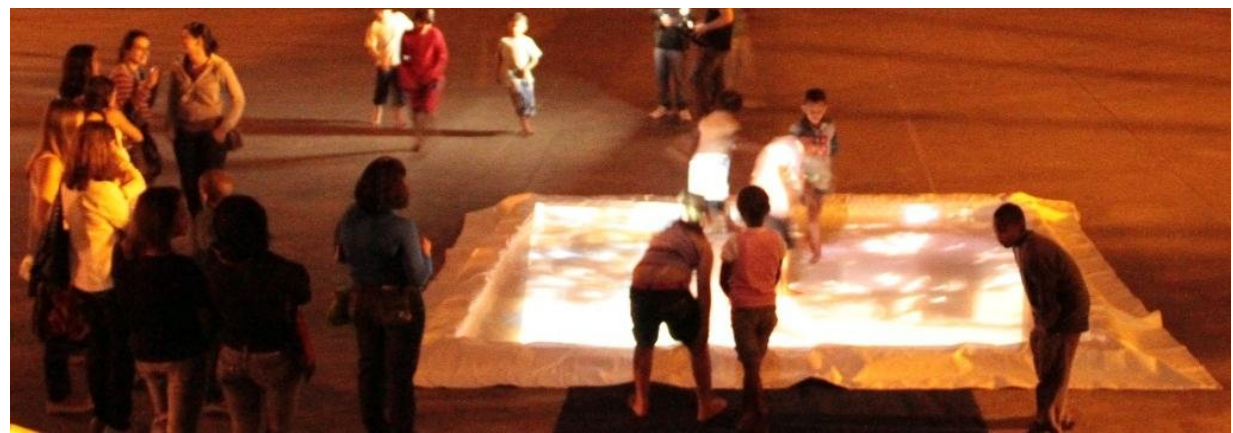

Foto 14: Professores, pais e alunos das escolas assistem a Instalação "Descoberto Incolor" de Kleber Damaso 
Destacamos os momentos de interatividade com a obra artística, como quando professores, pais e alunos puderam 'entrar e ajudar a construir a obra', por exemplo, na instalação "Descoberto Incolor" de Kleber Damaso (foto 15). Ao propormos esse tipo de vivência, aceitamos o desafio colocado por Marques (2000, p. 42): "A participação (o fazer) dos espectadores nos trabalhos artísticos é mais um desafio que se coloca diante da cultura digital que estamos vivendo [...]."

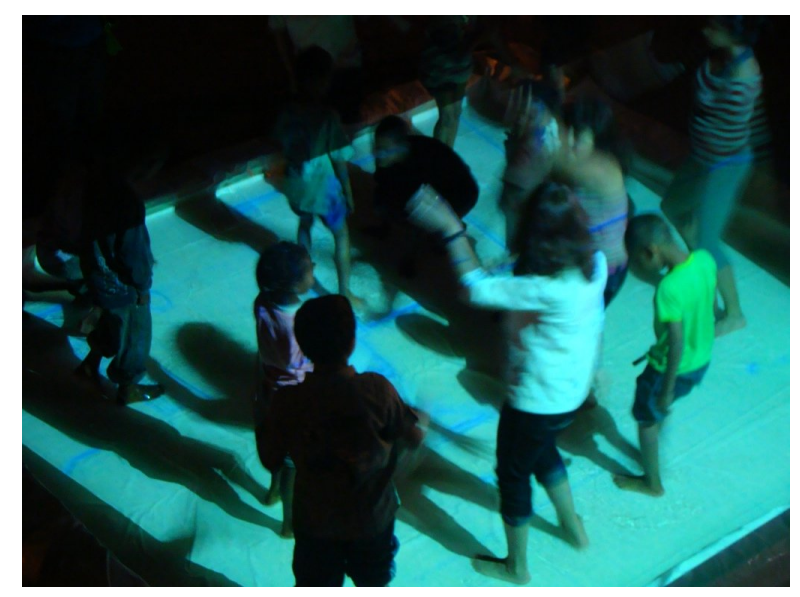

Foto 15: Momento de interatividade de professora e alunos de uma escola com a obra "Descoberto Incolor" de Kleber Damaso

Os pais e professores também foram convidados para assistir os espetáculos de dança "Ladrilho, Ladrilhando e Brincando" que acontecem todo final de semestre e que têm obras coreográficas cujos intérpretes-criadores são seus filhos ou alunos e outros artistas convidados da UFV e de Viçosa (fotos 16, 17 e 18). 


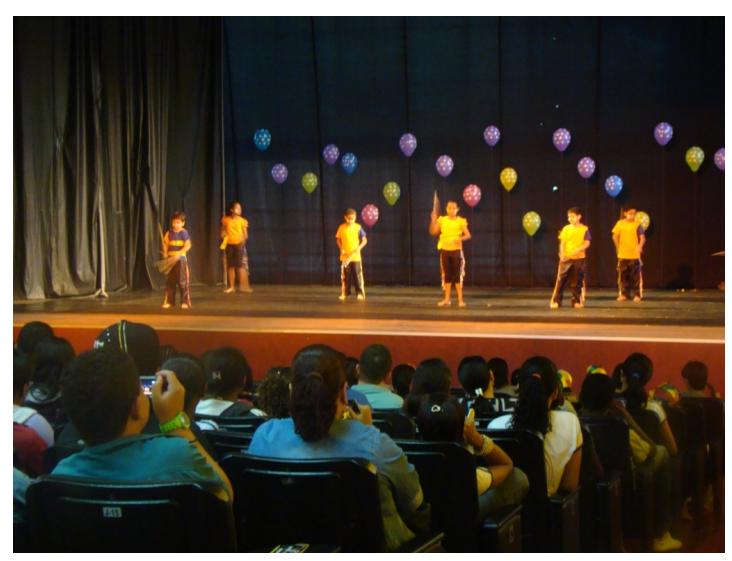

Foto 16: Público assistindo apresentação de alunos da Escola Dona Nanete na mostra de dança

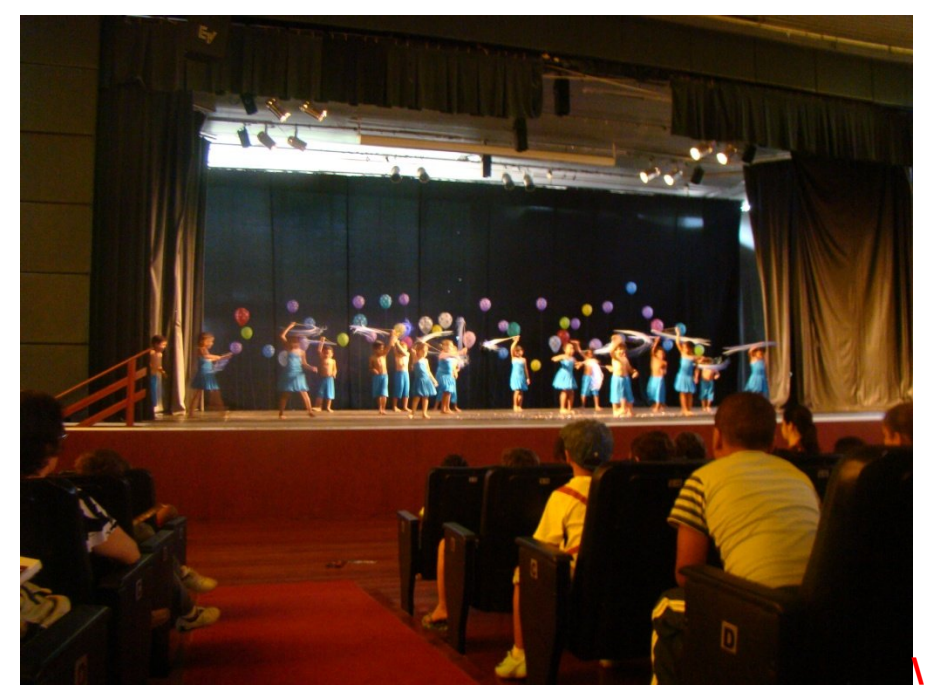

Foto 17: Público assiste coreografia dos alunos da Escola Anita Chequer na mostra de dança 


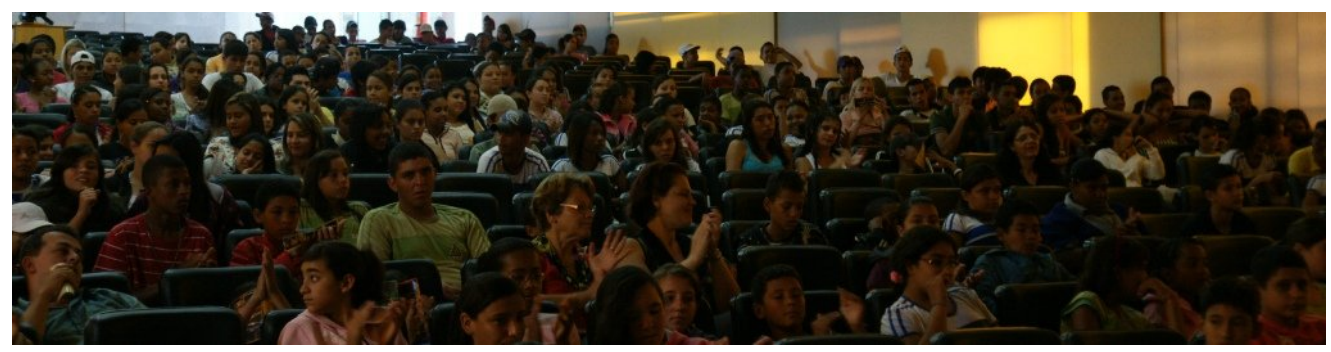

Foto 18: Pais e professores dentre o público presente assistindo a Mostra de Dança "Ladrilho, Ladrilhando e Brincando"

Foi um momento importante na formação artístico-cultural dos professores quando estes assistiam os ensaios dos alunos, ao longo de cada semestre, para apresentação nas mostras "Ladrilho, Ladrilhando e Brincando" (vide foto 19 professora acompanhando um ensaio dos alunos na escola). Nessas ocasiões, os professores podiam observar que o processo que gera o produto exige, realmente, muitas horas de laboratórios de criação, utilização de estratégias de composição coreográfica, dedicação, repetição, limpeza e assim por diante. Como afirma Strazzacappa (2003): "Os poucos minutos que dura a apresentação no palco encobrem horas de aprendizagem, preparação técnica, criação, ensaio, elaboração de figurino, iluminação, maquiagem, cenografia, gravação de trilha sonora etc.." (s/p). 


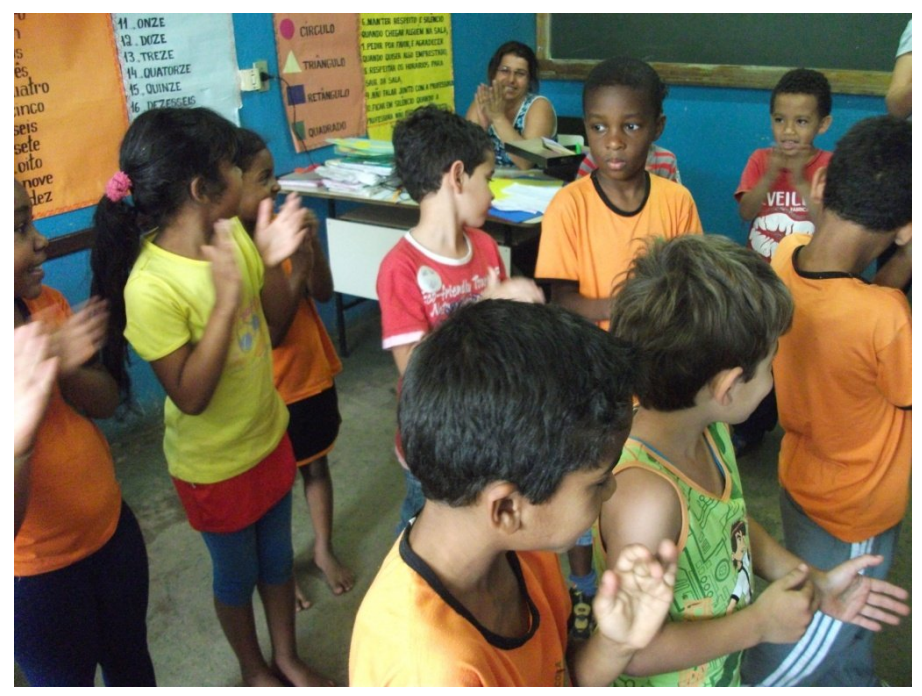

Foto 19: professora na escola participando de ensaios dos alunos para a mostra "Ladrilho, Ladrilhando e Brincando"

Alguns desses ensaios eram feitos no teatro, e se tornaram momentos ricos de aprendizagem para os alunos e para os professores também sobre iluminação, marcação de palco, entradas e saídas das cenas, como se comportar nesse espaço, dentre outros (vide fotos 20 e 21).

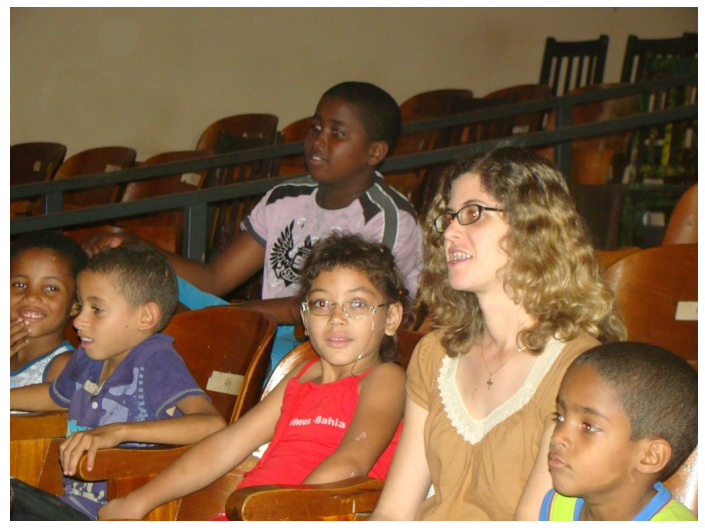

Foto 20: professora no teatro participando de ensaios dos alunos para a mostra "Ladrilho, Ladrilhando e Brincando" 


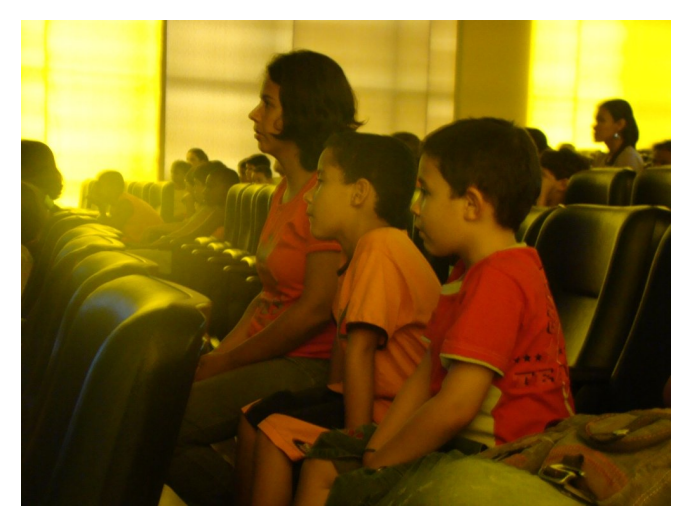

Foto 21: Professora assistindo o ensaio no teatro com seus alunos

Outro momento significativo para que os professores pudessem ampliar seus referenciais estéticos era quando assistiam a própria mostra "Ladrilho". Eles viam o produto (vide foto 22 professores apreciando a mostra), e nós podíamos observar o respeito com o qual o tratavam, pois tinham acompanhado e auxiliado em todo o processo e, assim, tinham realmente vivenciado o quão trabalhoso e árduo tinha sido produzir um produto final de qualidade. Nesse sentido, afirma Nogueira (2010): “o incentivo à formação cultural dos professores, por meio da frequência a eventos artísticos e de experiências estéticas, aponta para a possibilidade de uma prática docente marcada pela autonomia e pela pluralidade" ( $p$. $6)$.

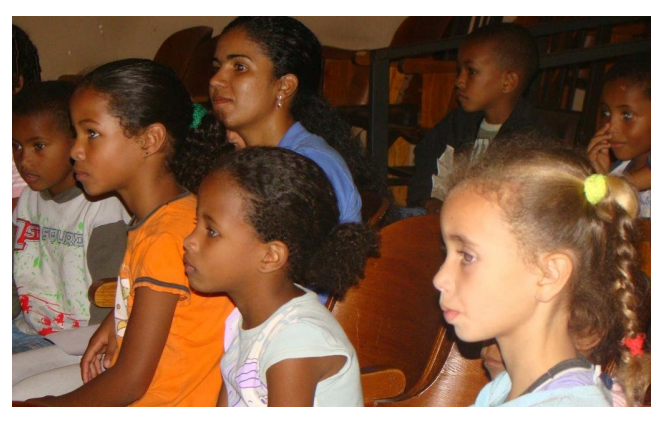

Foto 22: professora e seus alunos apreciando a mostra "Ladrilho" 
A mostra era geralmente finalizada com um momento de diálogo com o público presente. Sugeríamos que o público se manifestasse podendo fazer perguntas, comentários, e pedíamos que apresentassem pontos positivos e negativos para qualificar o processo e o evento artístico. Nesses momentos, ouvíamos geralmente muitos elogios por parte dos pais, diretores e professores. Apesar de sempre solicitarmos que apontassem falhas e/ou lacunas, a fim de que pudéssemos aperfeiçoar o projeto, havia sempre um retorno muito gratificante em relação aos trabalhos que desenvolvíamos. Alguns pais afirmavam que tinham observado claro aumento na capacidade expressiva corporal de seus filhos, por exemplo, um pai afirmou: "Fiquei realmente surpreso quando vi meu filho dançando no palco. Como ele é bastante tímido, nunca achei que fosse deixar a vergonha de lado e ir lá e fazer o que fez. Mesmo em casa, ele fala muito mais sobre o que acontece na escola, e fala geralmente sobre as aulas de dança e os ensaios da mostra". Um exemplo de comentários positivos foi quando uma professora pegou o microfone para falar: "O projeto foi a melhor coisa que aconteceu na nossa escola esse ano!" (vide foto 23 professora elogiando o projeto no microfone).

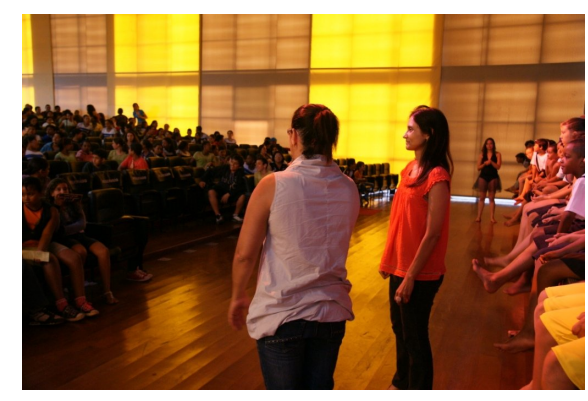

Foto 23: Após o espetáculo, momento de diálogo com o público — professora de uma escola elogia o projeto

Para os professores, outras possibilidades de enriquecimento cultural surgiram durante as inúmeras apresentações de gêneros diversificados de dança que ocorreram várias vezes nas instituições, principalmente nas escolas (fotos 24, 25, 26 e 27). 


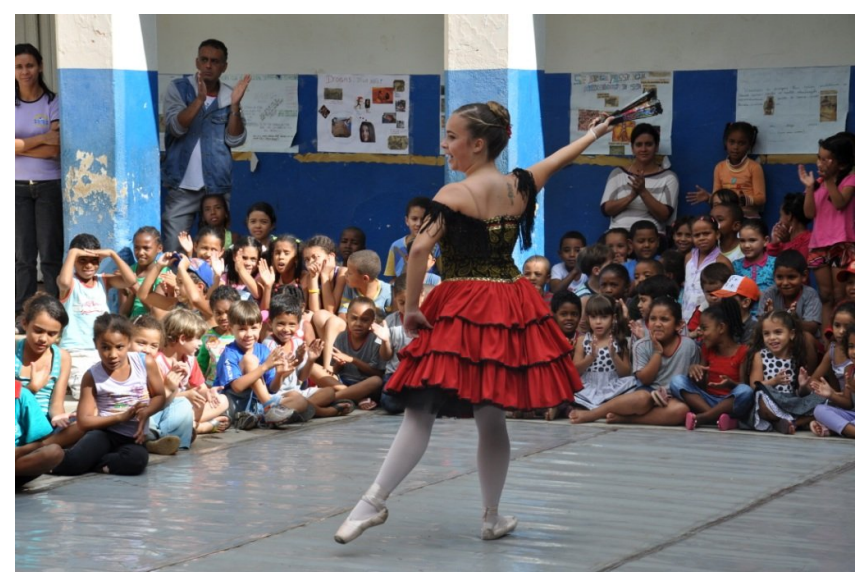

Foto 24: Professores e alunos das Escolas Dona Nanete e Maria José Santana assistem apresentação de balé clássico

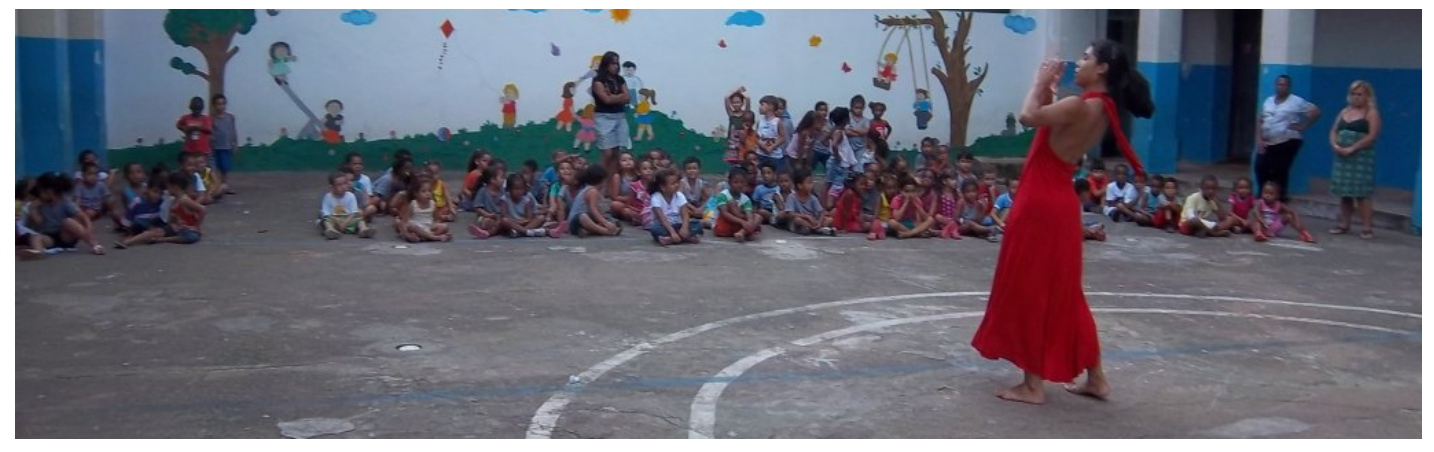

Foto 25: Professores e alunos das Escolas Dona Nanete e Maria José Santana assistem apresentação de dança contemporânea 


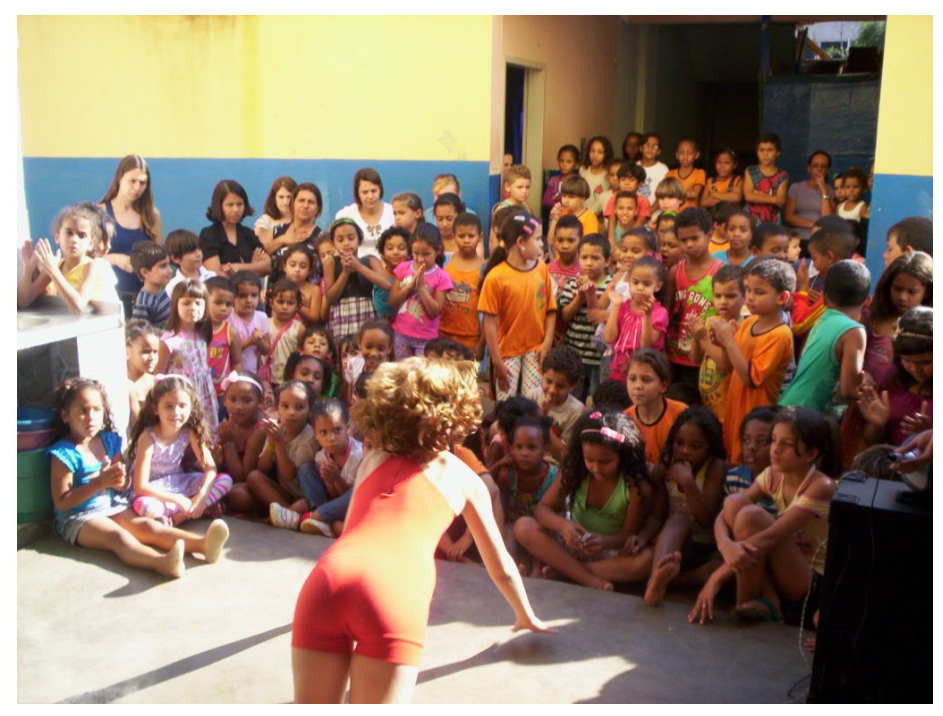

Foto 26: Professores e alunos da Escola Anita Chequer assistem apresentação de dança contemporânea

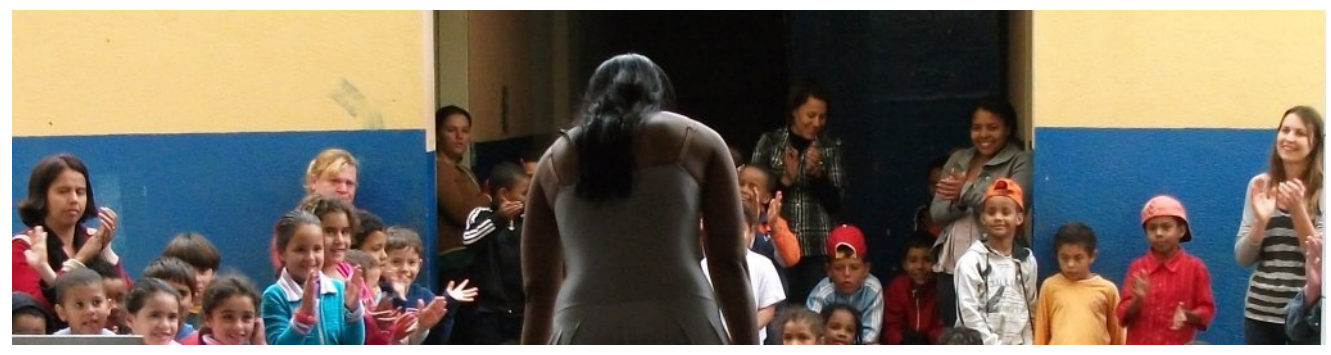

Foto 27: Professores e alunos da Escola Anita Chequer aplaudem bailarina após terem assistido apresentação de sapateado

A fruição da Mostra "Ladrilho" pelos pais também foi muito importante para o que Strazzacappa denomina de "educação estética de pais"; segundo a autora, a maioria das pessoas acreditam "que após as aulas de arte as crianças devem expor suas criações, levar para casa o produto de seu trabalho como forma de comprovar que algo de concreto foi realizado nessas aulas. Essa expectativa é mais alimentada por parte dos pais [...]." (2003, $\mathrm{s} / \mathrm{p}$ ). O produto do nosso trabalho era a mostra de dança, mas que era fruto de um processo de um semestre (não um trabalho pontual) e cujas obras constituintes, as 'coreografias', os próprios alunos ajudaram a criar e compor durante vários meses. Para os pais, os 
momentos de fruição desse produto eram oportunidades para eles aguçarem seus olhares e auxiliaram na construção de um saber sensível (vide foto 28 mães de alunos em momento de fruição da mostra de dança).

Tanto pais quanto professores vivenciaram a fruição da dança em teatros, a maioria pela primeira vez, por meio desse projeto.

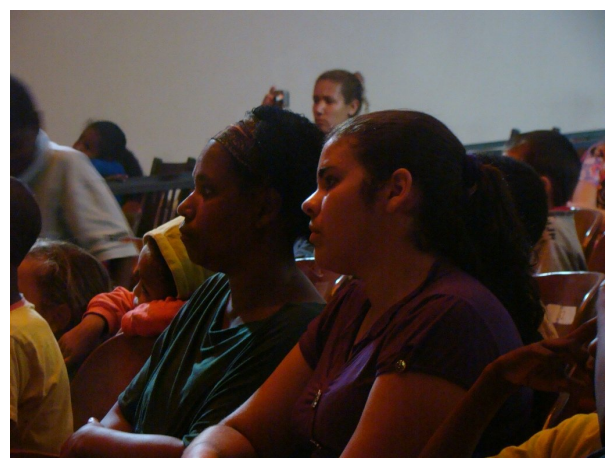

Foto 28: mães de alunos em momento de fruição da mostra de dança

\section{PROFESSORES E PAIS PARTICIPAM DO PROJETO POR MEIO DE MÍDIAS DIVERSAS}

Para potencializar nossas propostas, estimulamos ainda pais e professores a participarem do projeto por meio de redes sociais: Educação em Artes no Facebook: <http://www.facebook.com/profile.php?id=100002536470092>; $\quad$ e do blog $<$ http://educacaoparaasartes.blogspot.com>. Criamos também um site do projeto que serviu como um banco de dados de publicações do projeto: $<$ http://www.educacaoparaasartes.ufv.br/index.php $>$. Além de fotos, notícias comentários, e artigos postados, grande parte desse material também foi colocado no "Mural de Dança" das instituições.

Outra forma de incentivar a participação e de incrementar a bagagem cultural de pais e professores foi a distribuição gratuita de um livro digital (documentário) intitulado Educação para as Artes (VIEIRA, 2010) que ficou à disposição para consulta, apreciação e empréstimo nas instituições. Professores e pais também puderam acompanhar as 
atividades do projeto por meio de jornais/informativos quinzenais distribuídos gratuitamente para cada aluno. Os educandos relatavam que levavam os jornais para casa e que eles eram motivo de gerar conversas com seus pais sobre o projeto.

\section{CONSIDERAÇÕES FINAIS}

O trabalho com os professores, além de ter lhes permitido vivenciar a dança como arte, acrescentando essa experiência em sua formação cultural pessoal e profissional, permitiu também que eles dessem continuidade ao trabalho (em dança ou por meio da dança) com seus alunos. Eles foram capacitados a se tornarem agentes multiplicadores das atividades do projeto. As oficinas de dança com os pais dos alunos tiveram o objetivo de promover a educação para e pela dança no sentido de enriquecer seu repertório corporal. Buscamos também promover momentos de sociabilização entre os pais, buscando ampliar a aproximação entre si mesmos e com as instituições educacionais, já que estas, muitas vezes, não lhes oferecem, de forma sistematizada, vivências artísticas enriquecedoras. Por termos obtidos resultados bastante positivos nesse trabalho, sugerimos que projetos similares sejam desenvolvidos em outras instituições educacionais brasileiras tanto do ensino básico como da educação infantil.

Após análise de falas e imagens dos pais e professores, bem como da observação participante que foi feita durante todo o transcorrer do projeto, ousamos afirmar que todas as propostas foram como uma "porta de entrada para experiências estéticas significativas e relevantes" (NOGUEIRA, 2010). Temos consciência de que as ações e reflexões desenvolvidas com os participantes foram apenas uma gota d'água de um oceano que é imenso e exige continuidade, perseverança e criatividade. Acima de tudo, precisamos do apoio de políticas públicas que venham a contemplar e assegurar esse tipo de iniciativa.

\section{REFERÊNCIAS BIBLIOGRÁFICAS}


BAGATINI, Eliana; MARONESI, Viviana da Rosa Deon; ENÉAS, Cinara Valency. A dança e seu papel na educação infantil: resignificando a prática pedagógica. In: Anais da $58^{\underline{a}}$ Reunião Anual da SBPC .Florianópolis. Julho/2006.

BHERING, E; DE NEZ, T. B. Envolvimento de pais em creche: Possibilidades e dificuldades de parceria. In: Psicologia: Teoria e Pesquisa. 18, 63-73, 2002.

BOND, Karen; STINSON, Susan W. "I feel like I'm going to take off!": Young people's experiences of the superordinary in dance. Dance Research Journal, num. 32 vol 2, 52-87, 2000/01.

"It's work, work, work, work": Young People's Experiences of Effort and Engagement in Dance. Research in Dance Education, num. 8 vol. 2, 155-183, 2007.

CARNEIRO, Maria Aparecida Lopes. A participação da comunidade escolar e suas implicações para a prática democrática da escola. Dissertação (Mestrado em Educação). Faculdade de Educação, Universidade de Brasília, 2002.

CARVALHO, Maria Eulina Pessoa de. Relações entre família e escola e suas implicações de gênero. In: Cadernos de Pesquisa [online]. 2000, n.110, pp. 143-155.

CASTRO, Edmilson de. Família e Escola: O caos Institucional e a crise da modernidade. Disponível em: <http://clm.com.br/espaco/info9aa/1.html >. Acessado em: 01.03.2011.

CIA, Fabiana; D’AFFONSECA, Sabrina Mazo; BARHAM, Elizabeth Joan. A relação entre o envolvimento paterno e o desempenho acadêmico dos filhos. In: Paidéia, 14(29), 277-286, 2004.

COSTA, Patrícia Variz da; LIMA, Maristela Moura Silva; VIEIRA, Alba Pedreira. A construção do processo ensino-aprendizagem escolar através de experiências corporais. In: Anais do Congresso Brasileiro de Ciências do EsportE, 12., 2001, Caxambu. Sociedade, ciência e ética: desafios para a educação física/ciências do esporte. Campinas: Colégio Brasileiro de Ciências do Esporte, 2001.

FARIAS, Jaide Zuleica de; SILVA, Rossano. Pais na oficina de arte. Anais do XVII CONFAEB/Congresso Nacional da Federação de Arte Educadores do Brasil: Arte/Educação Contemporânea: narrativas do ensinar e aprender, 2007. Disponível em: <http://200.18.6.3/aaesc/comunicacoes/jaide zuleica de farias e rossano silva.pdf> acessado em 20 de janeiro de 2011.

FERREIRA, Sara Lúcia G.; TRICHES, Márcia Andréia. O envolvimento parental nas instituições de educação infantil. In: Revista Pedagógica. UNOCHAPECÓ, 11 (22) Jan./Jun. 2009. 
GREEN, Jill. Student bodies: Dance pedagogy and the Soma. In: BRESLER, L. (ed.), International Handbook on Research in Arts Education, pp. 1119-1132), The Netherlands: Springer, 2007.

LABAN, R. Dança Educativa Moderna. São Paulo: Ícone, 1990.

LOPONTE, L. G. Experiências estéticas e linguagens artísticas: inquietudes e experiências estéticas para a educação. Disponível em: $<$ http://tvbrasil.org.br/fotos/salto/series/10343907-formacaocultural.pdf $>$. Acessado em: 09 de fevereiro de 2012.

MARQUES, I. A. Dançando na Escola. São Paulo: Cortez, 2003.

. Apreciação e Interatividade: Casos que dançam. Disponível em:

$<\quad$ http://www.revistas.univerciencia.org/index.php/comeduc/article/view/4472/4194>. Acessado em 15 de fevereiro de 2012.

McNIFF, J.; WHITEHEAD, J. Action Research: Principles and Practice. United Kingdom: Routledge, 2002.

MORAES, Maria Candida. Ecologia dos saberes: complexidade, transdisciplinaridade e educação - novos fundamentos para iluminar novas práticas educacionais. São Paulo: Antakarana/WHH - Willis Harman House, 2008.

MUNDIN, A. C. R. Dança na Escola: uma experiência de arte educação no Ensino Médio. In: Diálogos Possíveis, 2, 2003.

NOGUEIRA, M. A. Formação cultural de professores ou a arte da fuga. Goiânia: UFG, 2008a.

. Experiências estéticas em sala de aula: possibilidades na formação cultural de futuros professores. ANPED, 2008b. GE-01: Educação e Arte. Disponível em: <http://www.anped.org.br/reunioes/31ra/1trabalho/GE01-4022--Int.pdf.> Acesso em 09 de fevereiro de 2012.

. Formação cultural de professores. Disponível em:

$<$ http://tvbrasil.org.br/fotos/salto/series/10343907-formacaocultural.pdf >. Acesso em 09 de fevereiro de 2012.

PARO, Vitor Henrique. Qualidade do Ensino: a contribuição dos pais. São Paulo: Xamã, 2000. 
SÁ, Virgínio. A (não) participação dos pais na escola: a eloquência das ausências. In: FONSECA, Marília; VEIGA, IIma Passos Alencastro (Orgs.). As dimensões do projeto político-pedagógico: novos desafios para a escola. Campinas: Papirus, 2001.

SGARBI, Fernanda. Entrando na Dança: reflexos de um curso de formação continuada para professores de Educação infantil. Dissertação de Mestrado (Artes). São Paulo: IA/UNESP, 2009.

STINSON, Susan.W. Dance in schools: Valuing the questions. In: WILDSCHUT, L. (Ed.), Colouring senses: Dance and the child international conference proceedings: Keynotes (pp. 48-53). The Hague: The Netherlands, 2006.

Issues in early childhood dance education research. In: RISNER, D; ANDERSON, J. (Org), Focus on Dance Education: Building Community (pp. 183-189). National Dance Education Organization Conference Proceedings (CD Rom), 2007.

STRAZZACAPPA, Márcia. Dançando na Chuva... e no chão de cimento. In: FERREIRA, Sueli (org). O Ensino das Artes. Campinas-SP: Papirus, 2007. p.39-78.

. Dança na Educação: Discutindo questões básicas e polêmicas. In: Revista Pensar a Prática. Num 6. p. 73-85, Jul./Jun. 2002-2003 Disponível em: http://www.revistas.ufg.br/index.php/fef/article/viewArticle/55 Acesso em 05 fev 2012.

VIEIRA, Alba Pedreira. The Educational Perspectives of Professors in a Dance Teaching Preparation Program: A Case Study of the Federal University of Viçosa, Brazil. In: Dance Current Selected Research. New York: AMS Press, 2007a.

- The Nature of Pedagogical Quality in Higher Dance Education. Dissertação de Doutorado. Temple University, EUA, 2007b.

- The Movements of Traditional and Transgressive Dance Teaching In Brazilian Higher Education: A Case Study. In: OVERBY,Lynnette Y; LEPCZYK, Billie. (Org.). Dance Current Selected Research. vol. 7. New York: AMS Press, 2009.

- Educação para as Artes. (Livro Digital). Visc. Rio Branco: Suprema (encarte); Belo Horizonte: BH Contorno Audio e Video, (DVD), 2010.

\section{SITES ELETRÔNICOS}

http://www.educacaoparaasartes.ufv.br/index.php

http://educacaoparaasartes.blogspot.com/

http://www.facebook.com/profile.php?id=100002536470092 
FORM AÇÃO ARTÍSTICO-CULTURAL DE PAISE PROFESSORES DE ALUNOS

DE INSTITUIÇÕES EDUCACIONAIS: A DANÇA EM FOCO 